\title{
Values and Evaluation from the Point of View of Psychopathology and Psychotherapy
}

\author{
Marie Lhotová
}

In contemporary psychology there are two main models of ordering the system of values. Besides the well-known hierarchical model applicable in cases when we examine individual values without examining the relationships among them, there is the non-hierarchical model, also called circular, ${ }^{1}$ which reflects the complementary as well as contrary relations of values. Within this framework the possibilities and limits of psychotherapeutic intervention based on an integrated approach with emphasis on logotherapy and existential analysis are formulated with reference to psychopathological categories defined in ICD X. The structure of the text arose with the help of students of Ethics in social work at the Faculty of Theology, University of South Bohemia, who formulated definitions of values, ordering of values, and searched for and formulated questions and answers. These are confronted with references to literature. A further part of the text is based on the results of the author's clinical psychological practice.

\section{Definition}

In the introductory session of the subject "Psychology of values" students of the second year of master's study of Ethics in social work at the Faculty of Theology, University of South Bohemia, were assigned with the task to define what is value and to order their values in the hierarchical as well as circular way. In the course of the two terms of instruction they further developed their concepts. This probe into the problem does not aim to meet quantitative criteria or reach a generalization of knowledge concerning values, it merely serves to give an idea of the space within which the topic of values can appear with university students.

Unsurprisingly, most definitions of value began with the words: Value is something... Something we respect, that is desirable for the individual and the group and leads one to define goals, norms, as well as to expected behaviour and action. Something that is important for humans, an important, irreplaceable aspect of life. Something that is worthy, e.g. is considered to be morally right or wrong, good or evil, in the psychological, social and physical sphere. Something that is important for personality development. Something we protect and wish to retain. ${ }^{2}$

The students' effort at defining has in effect lead to the formulation of Kluckhohn, ${ }^{3}$ who defines values as explicit or implicit conception of the desirable, which affects how the individual or group chooses among the available modes, means and goals. They also came close to Max Scheler's statement in referring to the emotional component of values in that the height of the value is determined by emotional response, and Frankl's statement that value is the best option in a situation. V. E. Frankl's claim that all hierarchies of values have one thing in common, which is life as an absolute value, was in the students' answers transformed into the value of health. 


\subsection{Form and meaning of values}

As output it was possible to form 8 groups, which were fundamental in defining: Values are (1) what determines our direction in life, expresses a goal, what we wish to achieve, what is the basic element, construction component, criterion of things (value as means and at the same time goal, by means of which we determine the direction of our life; we are guided by values and aim towards something; something that points in what direction one should conduct action and that helps one decide; values determine our goals and the path we take in life); (2) what specifically guides, determines and affects a) behaviour and decision-making (value is subjectively-objective determination of the goal object which leads one to certain action and behaviour; according to values one decides how to act; value is one's preference in the course of life), b) thinking (what one respects and grounds opinions in), c) emotions (what one perceives as good or bad), d) attitudes (what one deems to be the most important criterion of everything else), e) motivation (value focuses, energizes and maintains behaviour); (3) what expresses relationship (value is an incalculable, inalienable attribute of a certain thing, act, relationship); (4) what expresses effort (what one earnestly follows; what requires one to strain existential effort); (5) what expresses will (to give something up; to retain what is important for the individual in such a way that she is capable of giving something up; for values one is willing to sacrifice something; what one can further work on in order to reach it and keep it; (6) what creates orientation (value is what helps one to be a "better human being", what drives one, what one respects and preserves, what helps one in life and is the axis of his acting); (7) what leads to meaningfulness (gives meaning to life; value is the meaning of life; value is what requires other life values to fulfil this meaning, what transcends human pilgrimage, in this sense values are irreplaceable); (8) a value can even be a character trait (honesty, truthfulness, industriousness, conscientiousness, selflessness, the good).

The students also often mentioned re-evaluation and change of values in the course of life under the influence of certain events including transitory changes in various age periods of human life. They mentioned that the value scale is affected by upbringing and happiness in life and the possibilities one has as such.

\subsection{Hierarchy of values and their relationships}

By means of using a combination of the hierarchical and circular model in work with values, an overview of values in hierarchy and in mutual correlation was obtained in the survey. According to frequency of answers values are summarized in this order: (1) health of one's nearest and one's own health; (2) family, satisfaction in family life, satisfied parents, mutuality and solidarity of family members, family environment, place of residence, home; (3) partnership, friendship, good relations with people, love, support, giving and receiving, respect, harmony; (4) community and its good, security, democracy; (5) employment, education, meaningful work, self-realization, competence, success, own growth, ambition; (6) freedom, independence, self-esteem, courage; (7) empathy, understanding, solidarity; (8) truth, sincerity, playing fair, justice; (9) money, property, ownership; (10) the traces one leaves by his life, one's involvement in life and death; (11) ability to be helpful; (12) possibility to learn, imagination, creativity; (13) good conditions for life (social state), living one's life so that it is meaningful and valuable; (14) faith, trust, spirituality; (15) truth, conscience, honesty, humility, selflessness; (16) joy.

Compared to the 36 universal values divided into 4 groups of personal, social, moral and com- 
petence values as stated in the classification of Milton Rokeach, ${ }^{4}$ the students' enumeration of values is parallel. The survey shows the area of possibilities how to deal with the study of values with university students. Experience from psychotherapy of the mentally ill manifests difficulties of formulation and content when values are mentioned. This probably has to do with the context of mental problems which negatively affect one's identity and are accompanied by the feeling of threatened self-worth. In this connection we look for the relationship of identity and values. A special place is occupied by the problem of value judgment. One of the first questions is whether, or how and why, to work with values in psychotherapy.

\section{Values in psychotherapy. The role of value system and evaluation in psychotherapy}

Cakirpaloglu ${ }^{5}$ presents two views of psychotherapeutic intervention concerning values. According to one it is necessary to work with values, especially when the individual structure manifests values that disrupt the functioning of the personality, or when psychotherapy of values appears to be effective in the context of the general recovery of a psychologically disrupted personality (Alfred Adler), when in the absence of a view of reality the values tyrannize the person. The other opinion, represented by humanist and existential psychotherapy, is rejection of any kind of psychotherapeutic intervention in the sphere of the patient's values. It refers to the concept of human freedom and self-determination of the individual development, which presuppose sovereign disposition over one's own personality and all of its aspects, where the value system naturally falls as well. On closer analysis it turns out that psychotherapeutic intervention here means direct interference, which can be represented as a moralizing approach to the psychologically disrupted individual, or effort to transfer the psychotherapist's value structures which she herself views as good, regardless of the context of the patient's life and experience so far. In this way psychotherapeutic intervention could resemble unrequested help and as such become unjustified.

\subsection{Values in existential analysis}

Existential analysis and logotherapy as one of the representatives of humanist approaches in psychotherapy work with values intensively in the context of personal existential analysis. In the psychotherapeutic framework it starts from an experience, or moves towards an experience nourishing the basic value expressible with the words "I am glad to be alive". In these words the individual encounters value. The value of life is a fundamental value prepared for realization in the acceptance of life, however demanding, however limited. In this sense value is construed as a state of being open to the world. Being open to the world allows one to live one's values. Only when one lives one's values, i.e., the ones she really affirms, does one realize herself. Thereby we move from fundamental value to the value designated as self-worth.

\subsubsection{Self-worth}

Self-worth (Selbstwert), defined similarily by Längle, Frankl, Kruse and $\mathrm{Kast}^{6}$ as biologically preformed emotion which develops and differentiates in each individual in relationship to relational persons, to a great extent independently of culture, can be construed as a primary emotion. Clinical observations therefore tend to study the feeling of self-worth as a peculiar 


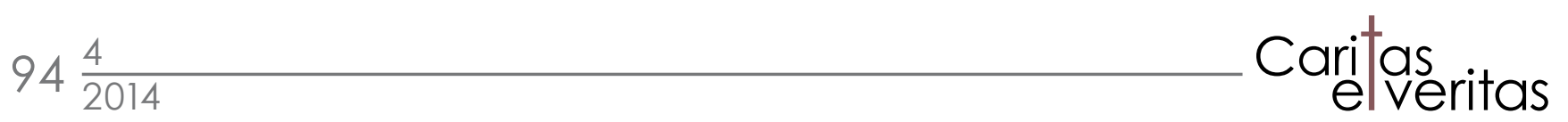

emotional sphere. The feeling of self-worth constitutes the foundation of the experience of identity. Even when life crises, depressions, anxiety or (psycho)somatic difficulties are compensated by grandiosity or arrogance, they cause a person not only to feel bad, but also to feel unworthy of acting as partner in contact. When one wants to overcome this feeling, she overcomes it with the help of defence mechanisms which can fill the healthy space of the individual and become her personality equipment, when one is no longer capable of insight into the origin of these defence mechanisms. This is how much psychoanalytic literature describes the origin of personality disorders, as well as anxious and other neurotic disorders. Put in a simplified manner, self-worth designates the feeling of one's own worthiness. The image of one's own self arises from internal and external evaluation. One needs that which is proper to her, unique, to protect oneself. Whenever she rejects what is within her, she threatens her own worth. In this context the topic of limits comes up. Determining the limits becomes difficult or impossible when the self is in danger. When this danger appears, relationship is threatened as well since only a self can relate. Subsequently there arises the danger that the non-relating person is not accepted by her surroundings. When one feels dependence or an asymmetry in a relationship and wants to present herself in good light, to please others, but has no resources to boost her own worth, she must then strive not to disclose her shortcomings so that her worthiness in the eyes of others does not suffer.

The induction of self-worth can be interiorized in psychotherapy by means of three steps. The process begins by intensified perception of oneself, which in fact means reflection of oneself aimed at the possibility of taking oneself seriously, starting dialogue with oneself and forming a relationship to oneself. Next one enters a relationship with her values and finally assumes an attitude to herself or to events concerning her.

\subsubsection{Personal-existential basic motivation}

The motives of actions are determined by values, their acquisition, protection, etc. ${ }^{7}$ Existential analysis works with life motivations, which help to submit the patients' values to analysis, beginning with the issue of the fundamental value of existing to life. This particularly concerns heading towards an affirmative answer to three basic questions related to motivation. An important aspect is the fact that value always has subjective relevance, as many leading axiologists (e.g. Perry, Buczyńska-Garewicz, Svanda) emphasize. ${ }^{8}$ Value is what is experienced as valuable, what is created by the particular experience of an individual. Interest is immediate acknowledgement of value constituted by the value itself. In this sense Buczyńska-Garewicz speaks of existential rooting of the value in the psyche. ${ }^{9}$ The questions concerning motivation introduced above derive from the first presupposition, which is that human beings can live in the conditions granted to them. Further presuppositions are not only the possibility, but also desire, i.e., the fact whether the human being wants to live in the given conditions, where existential analysis construes wanting as affirming a value. The third motivation is to be allowed to live and to act as one wants, as one is, and to assume responsibility for it, without the individual following and reacting to the requirements of other people. The last point, a fourth motivation, is the answer to the question what a human being should be like in order for her life to be meaningful.

Existential analysis will not teach a patient new or different values; it will rather help her to work out what is most important for her, what she can stand for, what she can assume respon-

\footnotetext{
7 Cf. Milan NAKONEČNÝ, Emoce, Praha/Kroměříž: Triton, 2012, p. 63

8 Cf. ibid., pp. 57-60.

9 Cf. ibid., p. 56.
} 
sibility for. According to the contemporary conception of existential analysis a human being is really free to search for meaning when all the four motivations are fulfilled, i.e., when she can accept the given situation, when she is addressed by a value and wants it, when she can ethically justify her behaviour based on conscience and recognizes the character of challenge which in the given time and situation can be represented as "this is what this moment is here for" ${ }^{10}$

In clinical practice there are many examples of situations, when the basic existential motivations are not fulfilled and it is necessary to deal with the individual presuppositions of full existence in turn, i.e., with acceptance, experiencing value and being oneself. The import of psychotherapy then consists in the task of dealing with one's own endangerment and with the fact that one is unable to accept, to deal with evident value deficiency, a situation when one has formulated one's values but gives up pursuing them. One subjectively perceives as meaningless when one experiences or does something one (1) cannot accept (e.g. a disciplinary measure), (2) has no relationship to (e.g. a task), or (3) feels she really ought not to do because she cannot assume responsibility for it. ${ }^{11}$ Existential analysis speaks of experiencing value, which consists in grasping and being grasped at the same time, in the unique sense that it concerns a particular person and her situational context.

\subsubsection{The framework of recognition}

Logotherapy and existential analysis not only distinguishes among creative, experiential and attitudinal values, it also distinguishes and explains the framework of universal, individual and personal values. Universal values are values that are typical for most people in everyday situations. They have been formed by society throughout history and result in traditions, habits, norms, customs and laws, whether they are determined by contracts, rules or commandments of the Decalogue. Substantially these are e.g. justice, loyalty, love, the good or truthfulness. These values are not subject to time, their formation and transformation often extends over many generations. They are values which orient one in life. A human being accepts many, though not all, common (universal) values into her individual concept (punctuality, loyalty, truthfulness). Individual values are updated from time to time; if not, they ought to be updated. Personal values are more or less situational. There are cases when one can live neither universal nor individual values because the situation requires the realization of another value. Although there are e.g. traffic rules as universal values and one as an individual acknowledges them as individual values, one nonetheless does not obey them when transporting someone who has had a heart attack. Such situation requires one to give preference to an absolute value, i.e., to the value of human life.

\subsection{The concept of internal integrity and harmony}

Cencini, whose concept of working with values can be employed in psychotherapy, points out the harmony of intrapsychic contents which must be formed in the human psyche, with respect to the unconscious sphere as well. ${ }^{12}$ It is an effort to attain a balanced state among the structural contents of the self, i.e., among needs, attitudes and values. We assume that an energy bound to one's basic needs is operative in human beings, as well as the motivating force of the ideals we believe in. The author considers values to be the motivating force. In his perception an integral personality is one whose attitudes are inspired by her values and at the same time use the energy of her needs. He considers harmony between values and needs to be

10 Alfried LÄNGLE, Nalézt přitakání životu, Propsy 2/1997, pp. 9-11.

11 Cf. ibid.

12 Cf. Amadeo CENCINI - Dana VOČADLOVÁ - Jiří SLABÝ, Psychologie seberealizace a autoidentifikace v Bohu, Praha: Paulínky, 1997, pp. 126-128. 


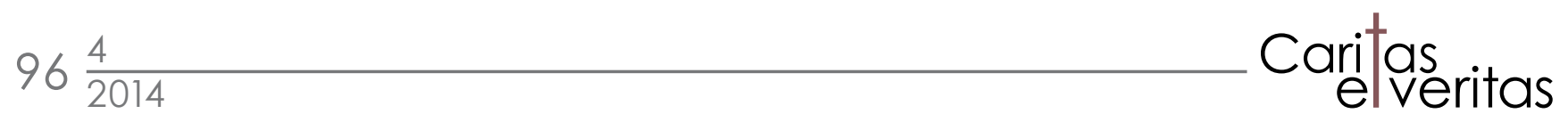

a source which helps to love the human being in God and God in the human being. He agrees with Frankl in stressing the importance of "being on the way" as accepting a "progressive harmonization" of human psychodynamic powers. To values he ascribes the task of directing one's instinctive life full of confusion, of showing the way and at the same time of effecting a strong pull in the direction of the individual way.

In psychotherapeutic practice the fundamental effects of the "pull" of values are well-known, which is why certain requirements are placed on them. A value must be transcendental, demanding, attractive (valuable). With respect to the possibility of changes a value can help reorganize internal life; as such it must be transcendental so that one avoids all convenient, reduced interpretations. When that is not the case there is danger "that it is merely a masked version of one's needs". ${ }^{13}$ At the same time the author underlines accepting needs as natural abilities and as a fundamental element of human spiritual development, as valuable power which prompts one to action and gives our being the excitement typical for "a human being who is alive". ${ }^{14}$ As in the case of existential analysis so in Cencini's theory a general lack of the ability to create values, and thus meaning in life, can be read as an element of risk and as defeat in the process of a human individual's realization. According to Cakirpaloglu (2004) the functional essence of value can in this context be condensed by defining two behavioural wholes. One is support of the process of adaptation to physical and social conditions, the other is the process of individual growth in transcending one's existence. ${ }^{15}$

\section{Evaluation}

Evaluation occupies a special place in the relation of subject to object. Just like freedom of choice, evaluation is part of basic human existential equipment. Values can be perceived as results or measures of evaluation. The concept of evaluation represents mutual interconnection with the concept of value, which Scholl-Schaaf ${ }^{16}$ formulates as follows: value can be understood as an abstraction of evaluation, and evaluation can vice versa be conceived as particularization of value in space and time. From this point of view evaluation is actual performance of values, i.e., realization of the model of preferences. It appears as "a complex process of the subject towards the object of evaluation, which is regulated by the kind and intensity of the value in question". ${ }^{17}$ This definition can be elaborated on in the sense that - if we are speaking of human interaction - the evaluated object is at the same time an evaluating subject who strives for knowledge, i.e., to understand the value system of the evaluating person in order to be able to take an attitude to the evaluation, or to correct her external expression according to expected effect on the evaluating person. It is therefore a case of social perception, further apperception as readiness to interpret on the basis of past experience, and finally valorization as determining the values which take part in the evaluation. In the evaluating process the value of independence or the value of positive feedback from the other can prevail in different persons according to the locus of control (Julian B. Rotter). Evaluation is creation determined by relationship as well as creation of the relationship and as such can be an interpersonally positive element, as well as a destructive one.

\footnotetext{
13 Ibid., p. 128.

14 Ibid., p. 130.

15 Cf. Panajotis CAKIRPALOGLU, Psychologie hodnot: Přehled pro humanitní obory, p. 403.

16 Cf. Milan NAKONEČNÝ, Emoce, p. 61.

17 Panajotis CAKIRPALOGLU, Psychologie hodnot: Přehled pro humanitní obory, p. 399.
} 


\subsection{Evaluation in psychotherapy}

Generally speaking, a psychotherapist in the psychotherapeutic process ought not to evaluate. However, the topic of evaluation is more or less intensively present at least from the point of view of the patient who feels evaluated, at least because in the aetiology of mental disorders there regularly appear non-specific symptoms such as insecurity, more or less perceived lower self-evaluation, anxiety, fear. Psychotherapy must confront these phenomena. Reduction of the accompanying unpleasant emotions often leads through artificial maintenance of positive evaluation feedback, which the patient directly or indirectly, often manipulatively demands. Fear of evaluation often presents a grave obstacle in psychotherapeutic work, because the patient focuses on being positively evaluated by the therapist, so that the path to labelling or naming the problems is difficult.

\subsubsection{Evaluation as a problem}

Evaluation in itself becomes a problem and a demotivating element when one is being decided about, even with the best intentions. She then loses the feeling that she can at least co-create life in a certain situation. When one is totally controlled in a certain situation, the feeling of self-worth disappears and gives way to other emotions, e.g. aggression, defiance, etc. Motivation can be intensified by evaluation, but also reduced or destroyed.

In general the parallel of aggression and value endangerment seems to hold. Where aggression appears, there it is necessary to focus on values. Similarly fear is direct indication of value endangerment. In depression emotional relationship to values is lost. When one lives a value one has affirmed, it does not cost as much vitality, effort and exhaustion. On this basis one can view both depression and stress and the burn-out syndrome. When only one of the values known from Frankl's classification - creative, experiential, attitudinal - significantly prevails on a long term basis, it is first indicated by stress.

From the point of view of patients, diagnostics in itself often evokes evaluation and one must admit that it is in fact the case, since the patient's state is compared to the values of health. Psychodiagnostics is an applied psychological discipline, whose basic task is determining, evaluating and measuring mental properties and states, as well as other characteristics of the individual. ${ }^{18}$ Especially when a patient is unable to view her mental disorder she often experiences a diagnosis in a problematic way, at the very least as labelling which she perceives as a threat in the sense that she will not be allowed to take the label off. The patient's idea that she is being continually evaluated by everyone is very common in psychopathology, in its irrefutability it often reaches the qualities of delusion. It is certainly imaginable how such a setting affects the quality of life.

\subsubsection{Evaluation and self-evaluation}

At the turn of the century Astrid Schütz extensively researched evaluation and self- evaluation. ${ }^{19}$ Her interpretation of the results resulted in findings important for psychology and psychotherapy. In this respect she points out especially the disproportionate relationship between the self-evaluation of an individual and evaluation of other people. She further points out self-over-evaluation in the social sphere and destructively disvaluating under-evaluation in persons with a low feeling of self-worth who experience envious emotions, which cause further disvaluation. She also points out that a high feeling of self-worth can be constructed "artificially" in the sense that one ascribes superiority to oneself by not accepting other people

18 Cf. Mojmír SVOBODA, Psychodiagnostika dospělých, Praha: Portál, 1999.

19 Astrid SCHÜTZ, Psychologie des Selbswertgefühls: Von Selbstakzeptanz bis Arroganz, Stuttgart, Berlin, Köln, 2001. 
as equal, because she would feel threatened. The motive is the desire to appear to others as a powerful person, with a high feeling of self-worth. In this context Lersch ${ }^{20}$ (1962) speaks of the "feeling of self-power", which he defines as the feeling of conviction that the given individual can affect the situation. From the point of view of depth psychology there arises the question whether an egocentric self-glorifying feeling of self-worth, which is affirmed by others because the subject wants it, really derives from evaluative feelings or whether it is rather a grand compensation of a bad feeling of self-worth.

A further problem is when values remain merely at the rational level and are not internalized, which gives rise to various irrational convictions and requirements such as "I must be nice to everyone in all circumstances".

Giving a chance to psychotherapy, i.e. focusing it on eliciting desirable changes in problems resulting from the patient's value system, presupposes working on understanding the patient's value categories and value scale at both the emotional and rational level. A therapeutic intervention in the value system can take place at the level of working with mapping values, or analysing values and value scales, as described especially by the cognitively behavioural approach. Another option is to allow values to stand out and follow them in certain contexts of motives, emotions and feelings related to the patient's life story.

In both directions it is a matter of working with how the patient views her own values and evaluating processes. Cognitive processes unroll individually and follow emotional and motivational properties. In both directions it is a matter of complex internal reflection resting primarily either on emotions or on rational search for and clarification of values. The first step in working with emotions is specifying non-adequate emotional reactions, searching for their foundation and for the subjective logic of emotional experience. Within these steps the values behind these emotions and subsequent acting can be identified, the causes of absurd evaluation and the foundation of passionate acting can be searched for, as well as agreement or disagreement with the logic of the intellect. For possible changes it is desirable to valorize present values or follow the path to new values.

In direct psychotherapeutic work with values Twokig and Crosby ${ }^{21}$ advise patients to proceed in 7 steps: (1) Distinguish between what is expected and one's own free choice. (2) Values help to set meaningful goals and to pursue them in a worthy way. (3) Define what subjectively matters in various areas of life. (4) Determine the importance of individual values. (5) Reflect to what extent the patient actually fulfils the relevant value area by her behaviour. (6) Set immediate goal that are in harmony with the values. (7) Learn to behave so that is in harmony with one's goals and values.

\section{Indications for therapeutic work with values}

In psychotherapeutic work mutual interconnection of individual and group values is assumed. Group values regulate the behaviour and affect the consciousness of group members, while individual value production is the most important source of group value transformation. ${ }^{22}$ The two groups of values - group and individual - can be in conflict and conflict can

20 Cf. Verena KASTOVÁ, Být sám sebou. Pocit vlastní hodnoty a zkušenost identity, p. 156.

21 Cf. Ján PRAŠKO a kol., Hodnoty a kognitivně behaviorální terapie, Psychiatrie pro praxi 2/2014.

22 Cf. Panajotis CAKIRPALOGLU, Psychologie hodnot: Přehled pro humanitni obory, p. 377. 
also arise at one of the two levels. It is assumed that conflict of values is a relatively permanent characteristic of personality or group. When such conflict is actualised, it manifests itself by ambivalence or inability in the sphere of decision-making and consequently by dependence, when one excessively needs others to decide for her. A consequence is submissive behaviour accompanied by helplessness and extensive fear of being abandoned. This results at least in a permanent need for support and reassurance when one is to make independent decisions. An individual with such needs desperately seeks the company of those who can provide support and help. Typically such a person permanently and passively relies on others, whom she expects to make decisions for her. Common is passive agreement with the wishes of other persons, timidity as well as insistence. ${ }^{23}$ When the need for dependence is not satisfied, the patient easily submits to depression or anxious states. The feedback which such a person receives often does not correspond to reality, since it is based on compassion or defiance. A typical feature is that thus afflicted persons find it difficult to express disagreement; in relation to lived values this accords with the thesis that if one lives a certain value which she affirms, she can also say "no".

\subsection{Overvaluation and undervaluation}

Milivojević distinguishes between two general groups of evaluation pathology ${ }^{24}$ - over-evaluating a certain value, i.e., hypervalorization, and under-evaluating a value, i.e., hypovalorization. Both types mean that in the structure of reactions there does not appear an adequate emotional reaction to the given value.

Hypervalorization causes a very intensive and long-term reaction in relation to disruption of or threat to an over-evaluated value, in the emotional sphere it causes anxiety or fear giving rise to behaviour inadequate to the situation. An example is the overvaluation of the value of health and the resulting state of threat in the case of a hypochondriac disorder. The hypervalorization of self-esteem and threat to self-esteem leads to shows of grandiosity, self- importance and uniqueness of the self, and at the same time oversensitivity to evaluation. This concerns the narcissist personality disorder, if the person is not taken as original and charming. The hypervalorization of sex leads e.g. to promiscuous relationships or deviant sexual behaviour. Hypovalorization, on the other hand, is the undervaluation of a value or ignoring it. It is imaginable so that the adequate emotional reaction related to a certain value does not occur. There is also no motivation to adequate behaviour in a potentially dangerous situation. An example can again be the value of health and gambling with health or self-accusing tendencies, or the hypovalorization of sexuality manifesting itself in sexual anhedonia or sexual aversion, or anxious or depressive disorders related to self-undervaluation.

\subsection{Inversion of value categories}

Values desirable and accepted in a given culture appear in an individual's hierarchy of values at the bottom of the value scale, and conversely, undesirable values are considered to be positive. The reflection in the behaviour of a person with values ordered in this way manifests asocial characteristics, when focusing on property, risk, gang, alcohol, or drugs threatens the value of human life as such. In this framework we can also include a strong and positive attitude to death directed to self-damaging behaviour, murder and suicide.

23 Cf. Ján PRAŠKO a kol., Psychické problémy u somaticky nemocných a základy lékařské psychologie, Olomouc: Univerzita Palackého v Olomouci, lékařská fakulta, 2010, pp. 176-177.

24 Cf. Panajotis CAKIRPALOGLU, Psychologie hodnot: Přehled pro humanitní obory, p. 400. 


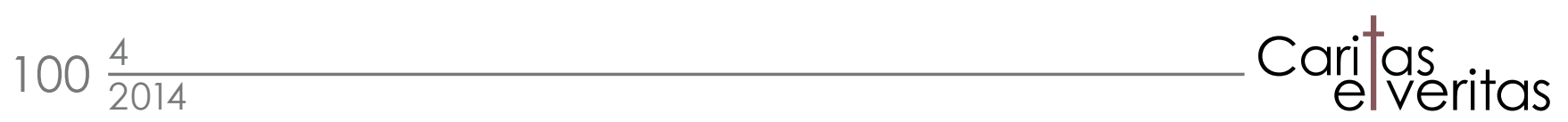

At the root of psychopathology there can - besides the inversion of value categories - also be a personal hierarchy which markedly differs from the socially acceptable hierarchy typical for a given culture. Such behavioural patterns tend to be stable and are not limited to episodes of mental illness. Problems then appear in adaptive social activity. Prestige, power, force, self-confidence, fight are acknowledged as values, all of them non-adaptive. The socially unethical behaviour of these persons reflects a lack of interest in the rights of others. Along with low frustration tolerance and a low threshold of aggressive eruption and violence these people are indifferent to social rules and obligations, morality and customs. Typical is cold disinterest.

\subsection{Transferring values to a different content frame}

Another moment which enters the pathological course of events is transferring a value into a different content frame, often without being aware of the inadequacy of such a move. This is regularly based on ego-defensive mechanisms. The value is e.g. the security of an adult man with his mother, but externally the mother's political views which he supports become a value.

\subsection{Conflict of values}

Conceptions of what is desirable are in various mutual relations. They can overlap, supplement one another, merge with one another, or exclude one another. Hnilica ${ }^{25}$ defines conflict of values as situations of logical contradiction in conceptions of what is desirable, quite independently of the psychological consequences of the contradiction. The same author considers potential conflict of values to be a universal attribute of every value system, since every system of values comprises some values that exclude one another. If mutually exclusive values occupy prior places in the hierarchy, the conflict is actualized and gains importance in a possible decompensation of psychological difficulties. Value conflict can be actualized by a situation or it can be a relatively permanent characteristic of a person or group. An actualized conflict of values can be to a greater or lesser extent conscious and manifest itself in the cognitive sphere. If it is to some extent unconscious, it rather manifests itself in the emotional or volitional or motivational sphere and the individual may be unable to identify it.

\subsubsection{Consequences of value conflict}

At the conscious level conflict of values gives rise to insecurity concerning what is to be considered right and desirable, what to do, what to think, what to feel, what to want so that it is right, what facial expression to assume, what to say, how to dress. It derives from an inability to identify unambiguously with one's own thoughts, opinions, attitudes, and choices. This insecurity gives rise to a changeability of opinions and attitudes and consequent dependent attitudes or persistent ambivalent evaluation of every relevant opinion, emotion, effort, goal, activity and result. The logical consequence is inability to decide when faced with the need to make a choice, standing in one place, absence of motivation, insecurity concerning the rightness of a choice already made or ambivalent attitudes to it.

Hnilica (2000) specifies the consequences of value conflict ${ }^{26}$ at three levels - emotional, motivational and behavioural. The emotional consequences of such conflict are increased occurrence of negative emotions and unpleasant tensions, decreased frequency of positive and

25 Cf. Karel HNILICA, Konflikt hodnot a kvalita života, pp. 385-403.

26 Jan PAYNE et al., Kvalita života a zdraví, Praha: Triton, 2005, p. 300. 
stenic emotions, changeability of emotions, distrust in one's own emotional reactions with a tendency not to succumb to them, not be guided by them and rather seek support from other "verified" sources. The consequence of value conflict at the level of motivation is aiming at removing the cognitive-emotional efficacy of the conflict, which leads to avoiding situations that lead to value conflict, reorganization of priorities in the system of values so that conflicting values do not occupy top places, directing attention away from the sources of the conflict by focusing on some activity or stimulation which is simpler and unconnected with the conflict, e.g. smoking or listening to music. In some cases it is effort at direct reduction of unpleasant emotions and inciting pleasant and/or stenic ones, principally by chemical means, using the effects of alcohol or drugs. Indirect reduction of unpleasant emotions and inciting pleasant and/or stenic emotions proceeds behaviourally, e.g. by therapy, relaxation, social contacts, sex, shopping, etc. Within this framework there also belongs forming behavioural "obligations", which make it easier to identify with one of the conflicting values. They can be represented by categorical moral judgments, unambiguously interpreted activities etc. The behavioural consequence of indecision, insecurity and ambivalent attitudes to choices already made can be returning constantly to steps already taken, correcting them, perfecting them, annulling them, the inability to complete an activity or the need for a disproportionately longer time for deciding and evaluating.

In psychopathology conflicts of values most often manifest themselves at the level of anxious disorders, or personality disorders. Typical is the dependent personality disorder and the histrionic personality disorder. In the case of long-term conflicts psychosomatic reactions can be expected.

\subsection{The problem of value transformation}

There are two fundamental topic spheres in psychotherapy. One of them is the issue of stabilizing and maintaining values and consistency in maintaining them, the other is the issue of value changes in interaction with the world in the context of one's own life, giving rise to consequent questions concerning the content and conditions of the changes. The content framework of these topics includes the abovementioned respect for values of the other.

Values are foundations of attitudes to such an extent that value changes and attitude changes regularly occur more or less in parallel. The object of analytical work with values is the individual measure of value resistance to changes and reflection of factors which inhibit or limit the change of value and subsequently attitude. If defending the consistency of own behaviour is very strong and values manifest extraordinary resistance in situations when there is no external tendency to change them, whether spontaneous or intentional, psychotherapy is concerned with understanding the content of values and the extent to which they are threatened from the patient's point of view. When perceptive accentuation, i.e., choosing and emphasising individual pieces of information which accord with the attitudes and values an individual respects, and perceptive negation, i.e., avoiding data which contradict current attitudes and values, with marked emotional component, is significant, then this stability probably enables orientation in complex situations and change gives rise to anxiety, insecurity, prospective tension, fear. Related factors are personality characteristics, age, type of values as well as group pressure, since conforming to the majority opinion helps to harmonize contradictory values, whether appropriately or inappropriately.

The ground for revising the extent to which given values are justified always are careful analyses of the cognitive and emotional foundation of the stated value. Assuming a certain measure 


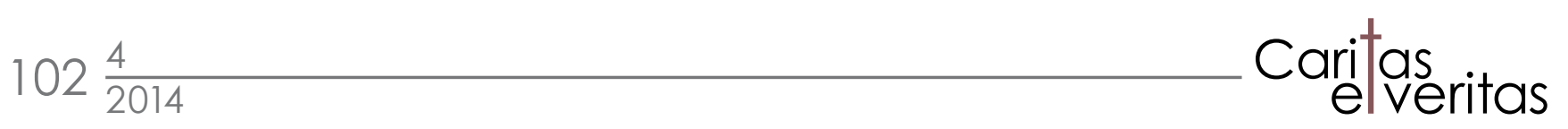

of the desirability of change, i.e., congruent or ego-syntonic change, Cakirpaloglu ${ }^{27}$ specifies levels of apperception and valorization as space for therapeutically entering the individual's value system in cases of evaluation disorders. They rather derive from the cognitive-behavioural attitude and represent a general interpretation, which fundamentally concerns defence mechanisms. The question remains if values are to change according to the character of the load situation.

\subsubsection{Apperception}

When working with values at the level of apperception it is rather a matter of assimilation as a process of assimilating to the given situation by interpreting events based on previous experience. Well imaginable is oppositional redefinition of meaning and affirmation. Redefining meaning works to change the meaning of a mental image which has given rise to a certain value linked to a negative emotion. This means that the new meaning is to reduce negative feelings and elicit positive ones, i.e., to guard against feelings of being injured, inferiority or sorrow in the situation of being abandoned after breaking up with a partner. Redefining helps to open up to another alternative, e.g. to the possibility of finding a better partner. Affirming an alternative value is a way to focus the individual on beginning to think positively by replacing a frustrating value with a new one. It gives rise to positive processes in the sphere of thinking and judgment and deliberation to another constructive action, e.g. in breaking up with a partner new, freer options that did not exist before open up. In searching for the actually possible or desirable these two modes or forms of defence mechanisms can rather be options of working in the sphere of crisis intervention. The aim is to support the patient to make an independent decision and choice by presenting a less painful alternative. The question remains whether in redefining or affirmation it is appropriate to threaten or devalorize a previous value, and thereby the individual who acknowledged it or lived for it.

\subsubsection{Valorization}

Therapeutic influence on the process of valorization is applicable when emotional and motivational problems derive from an activated value, but the interpretation of the resulting situation remains the same, let us say normal. Therapeutic intervention takes place in three phases, which are devalorization, inhibitory hypervalorization and finally restructuring of value. In the first phase the significance of the activated value is reduced with the aim that the patient ceases to respect a certain value, so that unpleasant feelings when the same value is activated are reduced. To prevent the occurrence of new conflict resulting from the process of devalorization of the original values and subsequent dissociation within the patient's personality, therapy by inhibitory hypervalorization works to activate an alternative value which is to eliminate the problem value. A condition of that is that a higher value is activated, e.g. the value of life, health, etc. ("I am glad to be alive, healthy"). The aim of the phase of restructuring values is to harmonize the individual's convictions with the corresponding value, whether the convictions are rational or irrational. It is supported by realization of goals and by the individual's experience.

\section{Development of values}

In all kinds of texts from the area of developmental psychology we find in various formulations the thesis that if there is no one to whom an individual attains basal trust and positive relationship, she does not attain it to herself. The various references in the text of this paper 
imply that without a relationship to oneself it is impossible to realize values. This is unambiguously confirmed by psychotherapeutic practice. Natural healthy development of values can be frustrated by an early childhood trauma or another form of moral psychopathology or social pathology. With a certain simplification we can look at the development of values from the point of view of the link of conscience and self-evaluation.

Denying conscience is linked to the narcissist personality disorder, a lack of conscience to the asocial personality disorder. In both types the ability to form a relationship to another is disrupted. According to Becker these disorders are pathological not only due to specific behaviour, but due to the relationship one assumes to this behaviour. ${ }^{28}$ The measure in which the psychological function of conscience is operative most probably determines the depth of the disrupted relationship and the extent to which the functioning of conscience is disrupted. Narcissism is defined as a lack of empathy and evident disability to take into account the subjective experiences and feelings of others. ${ }^{29}$ There is no willingness to self-examination because the patient's goal is to defend the ideals of her own self. An idealized self-image is a value and the goal is to maintain it. To maintain their self-image people project their own imperfection to others. Persons with the asocial personality disorder are a typical example of those who have transferred values to another level, so that they behave as if they had the right to lie, cheat and murder and lack all form of self-doubt and self-criticism. They take interest in others for self-stimulation, building self-love and/or material values, in the absence of remorse for injuring others.

\section{Conclusion}

Although this text opens the topic of the possibilities of psychotherapeutic work with values and explains the psychological difficulties linked to various types of problematic experiencing of emotions linked to the function of evaluation and value creation, it comprises but a small part of the extensive topic of psychotherapy and psychology of values. Modern psychotherapy often presents its effort at neutrality and unconditional acceptance, unhampered with value categories. At the same time it recommends positive evaluation and appreciation. Concerning this trend Raban very openly states that value freedom in psychotherapy is a myth and maintaining value reserve is a dangerous ideological temptation, because values then covertly return by the back door and subliminally infiltrate the therapeutic process. ${ }^{30}$ It remains to be added that any psychotherapeutic intervention in the sphere of values presupposes knowing one's own personal value categories, since every intervention method and every theory of personality and development implies evaluation, and also that value conflicts or diverging value conceptions of the main participants of the psychotherapeutic process - the psychotherapist and the patient - can prevent the successful realization of psychotherapy.

\section{Values and Evaluation from the Point of View of Psychopathology and Psychotherapy}

Abstract Examining what are values and reflecting on how important the discussion concerning them is in psychotherapy is fairly acute from the point of view of psychotherapeutic work, especially since va-

28 Cf. Christina BECKER, Jádro věci: Individuace jako etický proces, Brno: Emitos, Nakladatelství Tomáše Janečka, 2007, pp. 82, 83.

29 Cf. Diagnostic and Statistical Manual of Mental Disorders IV, Washington, DC: American Psychiatric Association, 2000.

30 Cf. Miloš RABAN, Duchovní smysl člověka dnes: Od objektivniho k existenciálnímu a věčnému, Praha: Vyšehrad, 2008, p. 163. 
$104 \frac{4}{2014}$ Caritas elveritas

lues find expression in the attitudes and ideologies of both patients and therapists. However, the views of psychotherapeutic work with values, value system and individual value hierarchies diverge. The paper aims to analyse the possibilities of psychotherapeutic intervention within the framework of examining the individual premises of value judgement. It mentions in detail the existential-analytic approach to value, whose explanatory framework allows for construing the issue of values basic for therapeutic work.

Keywords value; value judgement; psychotherapy; meaning 